\section{EMBRYRIDDLE}

Aeronautical University

SCHOLARLY COMMONS
Journal of Aviation/Aerospace

Education \& Research

Volume 13

Number 2 JAAER Winter 2004

Article 9

Winter 2004

\title{
Training Levels and Methodologies for Glass Cockpit Training in Collegiate Aviation
}

Richard O. Fanjoy

John P. Young

Follow this and additional works at: https://commons.erau.edu/jaaer

\section{Scholarly Commons Citation}

Fanjoy, R. O., \& Young, J. P. (2004). Training Levels and Methodologies for Glass Cockpit Training in Collegiate Aviation. Journal of Aviation/Aerospace Education \& Research, 13(2). https://doi.org/ 10.15394/jaaer.2004.1558

This Article is brought to you for free and open access by the Journals at Scholarly Commons. It has been accepted for inclusion in Journal of Aviation/Aerospace Education \& Research by an authorized administrator of Scholarly Commons. For more information, please contact commons@erau.edu. 


\title{
TRAINING LEVELS AND METHODOLOGIES FOR GLASS COCKPIT TRAINING IN COLLEGLATE AVIATION
}

\author{
Richard O. Fanjoy and John P. Young
}

\begin{abstract}
Modern commercial aircraft use extremely complex and sophisticated flight instrumentation systems that present training concerns for the aviation industry and collegiate aviation programs. The authors sampled 42 four-year collegiate flight-training programs to determine their current program emphasis on "glass cockpit" training and plans for curriculum enhancements in that area. Although nearly fifty percent of sampled program administrators believe instruction in flight automation is critical to the success of their graduates, most cite cost of materials and competing curriculum priorities as reasons to defer such instruction to future employers. The authors suggest that program enhancements are within the reach of modern college aviation programs and offer suggestions for three different levels of glass cockpit training.
\end{abstract}

Automated flight instrumentation began to appear in the commercial fleet in the early 1980 s (Hughes \& Dornheim, 1995). The move to flight automation began in response to increasing aircraft systems complexity and the requirement for an improved pilot/aircraft systems interface. Since the introduction of "glass cockpit" aircraft, a corresponding worldwide reduction in air transportation aircraft accidents and incidents seems to suggest the value of that expensive technology (Billings, 1997). With the growth of automated instrumentation, however, has come concern over new trends in accidents and incidents that are attributed to flight automation inadequacies or pilot inability to master automated systems. Weiner (1989) notes that many automation related accidents/incidents reflect pilot difficulties with vertical navigation modes. Mc Crobie et al. (1997) have studied automation accidents extensively and found that pilots frequently complain of automation system surprises during critical phases of flight. The prominence of new technology flight instrumentation and problems associated with its use has prompted many collegiate flight program adminictrators and edtucators in investigate flight automation systems, both to improve the pilot/systems interface during training and to adequately expose students to these systems prior to employment. The expense associated with training aircraft, flight training devices, and materials that employ flight automation, however, has convinced many program administrators to defer this training to the airline industry. This paper will present background information on the development of "glass cockpit" technology and current issues associated with such systems. The authors will also present a survey of four-year collegiate aviation educators regarding the current state and future of glass cockpit training in their programs. Finally, the authors will discuss several interesting training opportunities in this area that may be useful to a broad cross-section of collegiate aviation programs.

First generation glass cockpit aircraft featured computer-generated instrument displays with color-coded indications for ease of interpretation. Early glass cockpit instrumentation was limited to an electronically actuated cathode ray tube (CRT) that prominently displayed aircraft attitude, and a second CRT that displayed horizontal navigation, weather, and traffic depiction. Initial systems had little instrument consolidation and did not have computer-generated systems integration (Roessingh et al., 
1999). Modern fully glass flight decks include two CRTs for each pilot, the primary flight display (PFD), and the navigation display (ND). These two screens consolidate all traditional aircraft instrumentation for ease of viewing and aircraft control. In addition, one or more multi-function displays (MFD) are provided to monitor engine performance and systems diagnostics. A flight management system (FMS) is also provided on the flight deck with one or more control display unit (CDU) heads that serve as a crew interface with the aircraft to input/receive performance and routing information. Although pilot transition from conventional "steam gage" instruments to first generation flight automation was fairly simple, modern flight decks have reached a level of complexity that is challenging for the most accomplished pilots. In addition, automated systems have placed the pilot a significant distance from the control-feedback loop and traditional training methods are barely adequate to prepare flight crew for flight automation use in line operations.

A modern electronic flight instrument system (EFIS) can present a variety of control and performance information. Each display presents a consolidation of instrument indications in a format that is easily scanned/accessed during routine flight operations. EFIS is complemented by an engine indication and crew alerting system (EICAS) that provides automated systems monitoring to alert pilots of abnormal indications, diagnose systems failures, and perform routine tasks. The flight management system interfaces with EFIS components to provide performance, and navigation data on demand (Roessingh et al., 1999). Other prominent flight automation aspects include a full-authority digital engine controller (FADEC), automatic thrust, automatic trim, heads-up displays, and fly-by-wire flight controls. Each of these features improves pilot workload and efficiency, but also adds an additional level of complexity. Such complexity presents a difficult challenge for new pilot hires and crewmembers transitioning from less complex aircraft.

The two primary manufacturers of commercial aircraft, Airbus and Boeing, have chosen different philosophical approaches to the use of flight automation. In recognition of the role of pilot error in most aircraft accidents, Airbus has elected to design automated aircraft systems with computer controlled "hard limits" that prevent a nilnt frnm exreeting set flight parameters surh as hank. angle of attack, pitch, and airspeed. Any attempt to exceed these parameters will automatically be countermanded by automated flight controls. Boeing automation systems are designed similarly, however provision is made for pilots to override automatic systems in all phases of flight (Witt, 2000). Each philosophy has its drawbacks, but airliners that employ each design are currently in wide service.

Problems associated with automated flight systems derive from the relatively complex systems options and requirements. Researchers have identified as many as 114 human factors that are related to flight automation (Funk \& Lyall, 1999; Lyall et al., 1997). Automation-related accidents occur when pilots fail to understand what automated systems are doing and why they are doing it. Analyses of 85 automation-related incidents by Fletcher et al. (1997) suggest that almost 29 per cent of the incidents resulted from improper automation use. Sarter and Woods (1992) conducted a study of line pilots who operate automated flight systems and found that most did not have a comprehensive understanding of system modes. Typical automation-related accident factors include cockpit confusion, reduced manual flight skills, automation malfunctions, loss of vertical awareness, and pilot versus automation conflicts. Sarter and Woods suggest that contemporary flight training programs do not consider the impact of complex interrelated automation systems during non-standard flight situations. For this reason, training programs need to consider cognitive models that will best support pilot mastery of automated flight regimes.

\section{SURVEY}

A survey of collegiate aviation programs was conducted for the purpose of assessing current and planned levels of glass cockpit technology training. This type of training was defined as including instruction in one or more of the following systems as part of the school's flight curriculum: FMS, EFIS, EICAS, and automation (such as autopilots and/or flight director systems). The authors anticipate the use of survey data to foster discussion between schools and vendors/manufacturers in the development of low-cost training aids and devices to achieve curriculum goals.

A telephone survey was developed to maximize contact with target schools for this study (Young \& Fanjoy, 2002). The sample population included all 42 schools listed in the University Aviation Association's Collegiate Aviation Guide (1999) that offer four-year aviation flight degree programs. It was assumed that schools with twoyear degree programs would have little room for substantial course work in this advanced avionics area. Over a two- 
month period, the authors were able to contact program administrators at 37 schools, for an $88 \%$ response rate. All information was kept anonymous.

\section{SURVEY RESULTS AND DISCUSSION}

The first survey question asked whether the program includes instruction in "glass cockpit" flight instrumentation. It was interesting to note that only slightly over half the schools (51\%) responded "YES" to this question. A majority of the remaining schools indicated they did not plan such instruction in the near future, citing curriculum considerations and cost of materials as two primary reasons for not doing so. A Likert scale from 1 (not important) to 5 (very important) was used to assess respondent attitudes towards this type of education. Schools already providing glass cockpit technology instruction rated this instruction as being very important ( 4.6 on a 5 point scale). Remaining schools also viewed this topic as important (4.0), but have elected not to present such material at this time.

The respondents were asked at what point in the curriculum they provided this instruction and approximately how many corresponding hours were dedicated to the topic. Approximately $2 / 3$ of the surveys indicated this material was presented following the commercial and instrument certificates/rating achievement, typically during the junior or senior years. Time for advanced flight instrumentation instruction ranged from 2 hours to 50 hours, with 17 hours as an average.

The authors were curious as to where schools found training materials used during the course of instruction in glass cockpit technology and automation. Responses included: gifts solicited from industry, partnerprovided resources from airlines and training organizations, staff contributions from former airline and corporate pilots, existing or enhanced school equipment, specially targeted grants, the internet, and leased training courseware.

Next, the survey identified the types of media and methods that were used (Figure 1) to teach this type of instruction and the perceived effectiveness of each. Note that the highest number of schools used lecture, video, computer programs, PowerPoint, and CD ROMs. Interestingly, however, the most commonly used means, lecture and video, were not viewed as particularly effective. The more interactive instructional media and methods, such as computer programs, FMS trainers, and flight training devices, were perceived to be most effective.

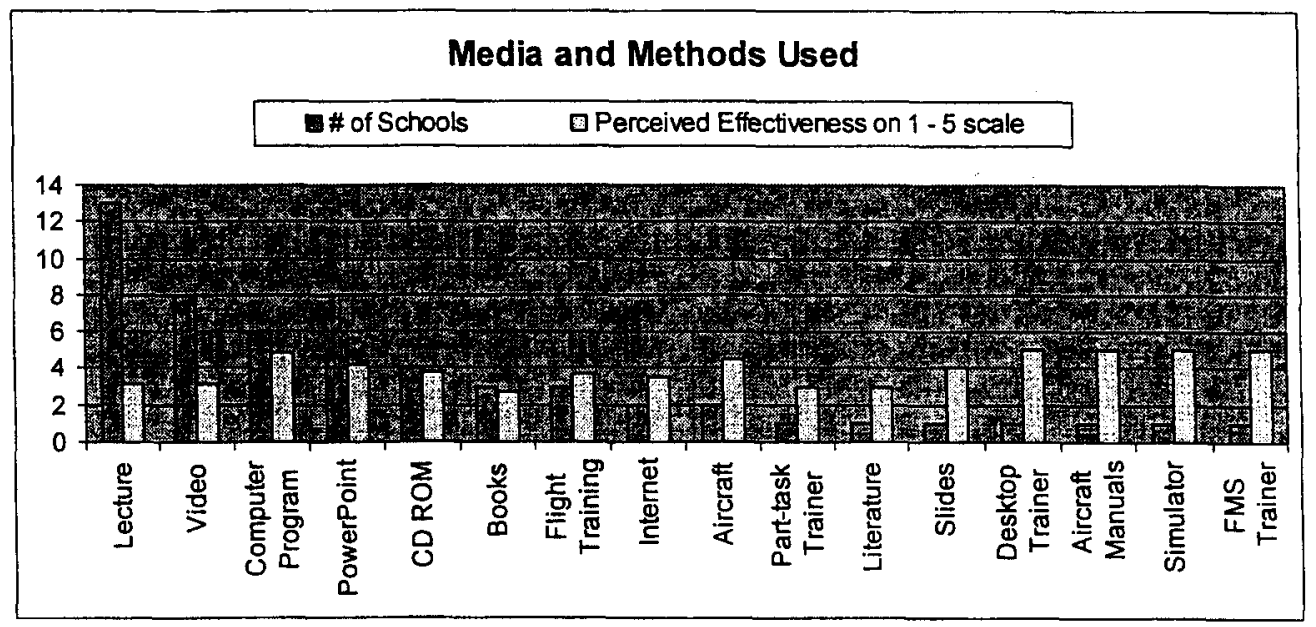

Figuro 1 Numher of schmnls versis nerceived effectiveness for various types of media and methods used to present glass cockpit technology instruction. 
The final section of the survey queried the respondents about likes and dislikes of their current training. Features they especially like included: high fidelity training software/CDs, hands-on capability, lowcost, interactive features, and dynamic presentations by qualified instructors. Some of their dislikes included: limited or non-existent free-play capability, lack of FMS information, unscheduled hardware/software problems, lack of detail, high cost of part-task trainers with glass, and potentially long periods between training and actual student application.

The final survey question asked respondents to discuss types of glass cockpit training aids and software that could be provided by vendors to meet their instructional goals. Ideas included: glass instrumentation in training aircraft, virtual flight decks, desktop trainers, PCATDs (personal computer aviation training devices) with glass, loaner or "retired" materials from airlines and other industry training organizations, and better video and computer presentations.

A consideration critical to colleges was that new flight automation training materials be designed to minimize user costs. Very few schools are financially able to purchase state-of-the-art equipment such as regional jet flight training devices (FTD), and the vast majority of schools have minimal funding support for the advanced training materials and/or devices. Most schools feel that flight automation training is important, but such implementation has been severely restricted in the past due to cost constraints.

\section{RECOMMENDED LEVELS OF GLASS COCKPIT TRAINING}

Survey findings suggest that most collegiate aviation educators believe some level of flight automation training should be included in a four-year flight program. The authors suggest three possible training strategies for presenting flight automation training in collegiate aviation programs: orientation, limited familiarization, and full glass cockpit integration. A description of each option and associated benefits/detriments will be discussed; specific vendors and manufacturers will not.

\section{Orientation}

Most flight automation instruction currently presented in college aviation programs is completed at the orientation level. Orientation level presentation is well suited to traditional classroom teaching. Lecture format can be used to convey elementary theory and functional aspects of new generation aircraft. Video, PowerPoint presentations, computer-based instruction via CDs or the Internet, and other printed/projected media can be used to enhance classroom presentation. While a large variety of media is available to showcase the basic material, instructor experience with automated systems is essential to adequately develop the presentation, stimulate discussion, and answer students' questions. Advantages of orientationlevel instruction include the relatively low cost and availability of instructional materials as well as adaptability to most modern classrooms. Student interaction with orientation materials can occur at several levels. For example, a video that describes the features of an automated cockpit may only provide passive learning. On the other hand, the instructor may require students to complete pencil and paper activities to reinforce systems knowledge presented in the video or conduct a field trip to an advanced flight training facility that features modern flight training devices. The primary disadvantage of orientation-level instruction is that the student does not receive "hands-on" practice with the actual or simulated equipment. They observe how it works but do not get to actually manipulate the device or fly the aircraft. Student feedback regarding orientation-level flight automation instruction in classes taught by the authors has been guardedly positive. Such students eagerly absorb any information on modern airplanes they hope to fly, but express concern that they do not get to apply the information in an actual operating context.

\section{Limited Familiarization}

Limited familiarization or partial integration could be used in the classroom, but may best be incorporated into a laboratory experience. Sherman and Helmrich (1997) suggest that part-task trainers are extremely important to automation training programs. They note that several studies highlight the success of free play in mastery of FMS in particular. This type of training allows the learner to directly manipulate and control various components of a newer technology aircraft, without going to the aircraft or a simulator. Inclusion of such devices as FMS trainers, part-task systems trainers, virtual cockpits, and computergenerated glass cockpits into the curriculum can more actively present newer technology to aspiring professional pilots. With this type of instruction, the student can manipulate the hardware (in the case of an actual part-task trainer) or use a computer to simulate the actions of an actual glass cockpit aircraft. The instructional devices 
might be "generic" (a piece of equipment that represents the class of aircraft) or it could be "type specific" (equipment that exactly replicates a particular aircraft in appearance and operation). With free-play capability, such devices allow the student to enter different operational scenarios. Students observe automation logic and how it functions to integrate various aircraft systems. However, the limited familiarization level of instruction does not provide comprehensive, hands-on instruction in a complete cockpit environment. Part-task trainers and instrument components do a good job of teaching a subset of the aircraft systems and operations, but do not fully integrate all of the components together in one training device. Such equipment provides a higher level of interaction and realism than orientation-level instructional aids, but at a significantly higher cost.

\section{Full Integration}

Full integration in automated flight system training devices is accomplished in a laboratory environment. Full integration utilizes all the systems and components experienced in either an actual aircraft type or a "generic" representative aircraft type, such as a regional jet. Each cockpit component is operational and accurately replicates the flight parameters and system responses of an aircraft. While an actual aircraft might be used for this purpose, such use is expensive and, in some cases, an unsafe means to accomplish the training objectives. Full flight simulators (FFS) and FTDs, particularly Level C and D FFSs, have been designed to very closely replicate actual aircraft. The level of systems sophistication is lower in flight training devices than full flight simulators; however, the FAA still allows some training credit for FTD use. The flight training devices are classified as Levels $1-7$, some of which are generic to the class of aircraft; others are type specific to the aircraft (Federal Aviation Administration. 1992).

At the full integration level of flight automation training, equipment supports student development in normal, abnormal, and emergency operations. In typespecific FTDs and FFSs, the control responses and systems accurately depict an actual aircraft. Operational aircraft training manuals may be used for instruction. In some equipment, airline training departments may conduct all training in a combination of these two types of training devices withmit the new nilnt ever leaving the ground. The newly trained pilot's first flight in an actual airplane may be a revenue flight with a check airman on board. Generic type FTDs, on the other hand, may be modeled after a specific airplane but are required to have flying characteristics similar to a particular category and class of airplane. These lower-level training devices may be used for Part 61 and 141 training credits.

The advantage of fully integrated flight automation training is that equipment facilitates student interaction with ground and flight environments using the "whole" picture of instrument and systems operations. Individual components can be studied while effects may be observed in other systems as well. Such training produces a more complete understanding of aircraft operation. The student is required to understand basic systems theory, operate systems, manipulate controls, and make decisions to "fly" this type of device. In an FFS or FTD, the student can make major errors and yet not affect the safety of the crew. This allows the instructor to observe student behaviors and actions that would not be allowed to develop beyond a certain point in an actual aircraft. The major detriment to the fully integrated level of instruction is cost. New FFSs typically cost in the $\$ 10$ to $\$ 20$ million-dollar range. Transferring equipment operating costs per hour to college students makes this option prohibitive. Although the potential to share user costs with industry for such devices has potential, many difficult issues must be addressed with such a strategy. Used FFSs may be found, although space requirements and maintenance upkeep also cause this to be a very expensive option. With the increasing capability and lower cost of component PCs, FTD costs are coming down and enhanced realism is available. Newer FTDs with visual systems, however, can still cost anywhere from about $\$ 200,000$ to $\$ 5$ million dollars. More schools are investigating the option of generic or type-specific FTDs to enhance this type of specialized training in collegiate aviation.

\section{CONCLUSION}

Modern automated flight systems have become commonplace in the aviation industry. Although the vast majority of collegiate flight programs believe that flight automation training is critical to the success of their students, few apply comprehensive training in this area. Most administrators cite the high cost of flight automation training materials and equipment as a major deterrent to progress. Also, many educators feel flight programs are currently overloaded with required courses and subiect matter, leaving little room for including additional topics, no matter how important. Finally, many administrators 
believe that the training section of an airline or other aviation employer should be the one to conduct advanced training in areas such as glass cockpits and flight automation. While the authors understand the current stance of aviation educators, they feel that it is critically important that professional pilot graduates have access to this body of knowledge in concert with other advanced topics they receive during the college program. Casner (2002) suggests that training accomplished in small aircraft, using current technology lower cost devices, such as the Garmin 430 or Bendix King KLN 94, will prepare students for more sophisticated FMS units found in many transport aircraft used by the airlines.

The authors suggest three levels of flight automation training for consideration by collegiate flight programs. Although most programs may find the orientation level of training well within their means, the authors encourage flight program administrators to investigate hands-on opportunities such as computer-based training aids and part task trainers for this critical area of instruction. Access to virtual cockpits with advanced flight instrumentation is available through online sources or CD media at reasonable prices from several vendors. In addition, participatory arrangements could be pursued through partner aviation industry sources. Although hard choices must be made to make room for this material in collegiate aviation programs, the authors believe such change will have lasting benefits for aviation college graduates and the aviation industry. $t$

Richard O. Fanjoy is an Assistant Professor of Aviation Technology at Purdue University. He currently teaches upper division flight technology courses that address advanced transportation aircraft systems/procedures, high performance aerodynamics, and flight automation systems. His research agenda includes pilot competency measurement, flight automation systems, and flight student cognitive development. A retired Air Force Command Pilot with extensive international experience, Professor Fanjoy has served in a wide variety of senior command positions and as a heavy jet aircraft flight instructor, check airman, and aircraft accident investigator/board president.

John P. Young is an Associate Professor of Aviation Technology at Purdue University. He currently teaches transport aircrafi systems and procedures, human factors, and crew resource management courses to professional flight students. In addition, he supervises instructors and students in the advanced flight simulator program. His research interests include human factors and educational teaching technologies. He holds Airline Transport Pilot, Certified Flight Instructor, and Flight Engineer Certificates. 


\section{REFERENCES}

Billings, C. E. (1997). Aviation automation: The search for a human-centered approach. Mahwah, NJ: Lawrence Erlbaum Associates.

Casner, S.M. (2002). Cockpit automation: for general aviators and future airline pilots. Ames, Iowa: Iowa State Press.

Federal Aviation Administration (1992). Airplane flight training device qualification (Advisory Circular 120-45A). Washington, DC: U.S. Department of Transportation.

Fletcher, G.C.L., Dudfield, H.J., Davy, E.C., Crick, J., Gorton, T., Russell, S., et al. (1997). Transition training and the glass cockpit. Proceedings of the Ninth International Symposium of Aviation Psychology. (pp. 237-242).

Columbus, $\mathrm{OH}$ : The Ohio State University.

Funk, K. \& Lyall, B. (1999). The evidence for flight deck automation issues. Proceedings of the Tenth International Symposium of Aviation Psychology. (pp. 105-110). Columbus, OH: The Ohio State University.

Hughes, D. \& Dornheim, M. A. (1995). Accidents direct focus on cockpit automation. Aviation Week and Space Technology, 1, 52-54.

Lyall, B., Niemyczyk, M., Lyall, R, \& Funk, K. (1997). Flightdeck automation: Evidence for existing problems. Proceedings of the Ninth International Symposium of Aviation Psychology. (pp. 848-852). Columbus, OH: The Ohio State University.

McCrobie, D., Alkin, M., Sherry, L., Feary, M., Polson, P., \& Palmer, E. (1997). Enhancing vertical navigation performance in glass-cockpit aircraft. Proceedings of the Ninth International Symposium of Aviation Psychology. (pp. 434-439). Columbus, OH: The Ohio State University.

Roessingh, J.J.M., Van Gent, R.N.H.W. Fletcher, G., Dudfield, H., Lodge, M., Koehl, F., et al. (1999). Training for the 'glass cockpit': Trends, problems and solutions. Proceedings of the Tenth International Symposium of Aviation Psychology. (pp. 985-991). Columbus, OH: The Ohio State University.

Sarter, N. B., \& Woods, D. D. (1992). Pilot interaction with cockpit automation I: operational experiences with the flight management system. The International Journal of Aviation Psychology 2, 4, 303-321.

Sherman, P.J. \& Helmreich, R.L. (1997). Training for use of automation: The value of 'free-play' as a complement to traditional transition training. Proceedings of the Ninth International Symposium of Aviation Psychology. (pp. 243-248). Columbus, OH: The Ohio State University.

University Aviation Association (1999). Collegiate Aviation Guide. (University Aviation Association Publication). Auburn, AL: University Aviation Association.

Weiner, E. (1989). Human factors of advanced technology ("glass cockpit") transport aircraft. (NASA Contractor Report 177528). NASA-Ames Research Center, Moffett Field, CA.

With, D. (2000). Airbus and Boeing-2 differing fly-by-wire philosophies. Professional Pilot, 3, 80-86.

Young, J. \& Fanjoy, R. (2002). [Survey of collegiate educators in 4-year aviation schools offering flight majors]. Unpublished raw data. 
